\title{
Physiological effect of Natural Penicillin Extract on Cassava Peel Media by Penicillium chrysogenum PCL501 on E.coli Infected Wistar Rats
}

\author{
${ }^{*}$ Onyegeme-Okerenta, B.M. and ${ }^{2}$ Ebuehi O. A. T. \\ ${ }^{I}$ Department of Biochemistry, Faculty of Science, University of Port Harcourt, PMB 5323, Choba, Rivers State, \\ Nigeria. \\ ${ }^{2}$ Department of Biochemistry, College of Medicine, University of Lagos, P. M. B. 12003 Idiaraba, Lagos, \\ Nigeria
}

\begin{abstract}
Some physiological effect of natural penicillin extract produced on cassava peel media by Penicillium chrysogenum PCL501 on E.coli infected Wistar rats were evaluated. Fermentation of $P$. chrysogenum PCL501 with cassava peels - an agro-waste- produced natural antibiotics. In vitro antibiotic activity of cassava peels culture extract was tested against two clinical bacterial isolates, namely, Bacillus subtilis, and Escherichia coli. The culture extract and standard drug (commercial Benzyl Penicillin) inhibited the growth $B$. subtilis and $E$. coli. Antibiotic activity of the culture extract was comparable with that of the standard drug. In vivo antibiotic action on Wistar Wistar rats infected with $E$. coli showed that the penicillin produced on cassava peel was potent as its administration leads to the recovery of the infected animals. Evaluation of biochemical indices of $E$. coli infected Wistar rats and treatment with extract confirms that the extract is a potent antibiotic. The haematological evaluation showed a significant decrease $(p<0.05)$ in platelet count in animals administered with both the extract and reference drug. Cassava peels are indicated as a suitable and cheap carbon source for the production of penicillin by P. chrysogenum PCL501.
\end{abstract}

Keywords: Cassava peels, Penicillium chrysogenum PCL501, Natural penicillin, Benzyl penicillin, antibiotic activity.

\section{INTRODUCTION}

Penicillium species are filamentous fungi; they are common contaminants which colonize a wide range of materials including wood, fabrics and leather objects and naturally thrive on plant wastes by penetrating the dead plant matter and utilizing the cell wall components as growth substrates. In 1943, P. chrysogenum, was discovered and has remained the species of choice for industrial penicillin production; it yields much more penicillin than $P$. notatum, the first antibiotics-producing fungus isolated by Alexander Fleming, or any of its derivatives ${ }^{[1,2,3]}$. Search for better strains of the organism, growth optimization, and development of available strains of $P$. chrysogenum by classical mutagenesis procedures have been centered at improving penicillin yields ${ }^{[4,5]}$. Although, these have led to the availability of cheaper and effective penicillin, further reduction in production cost of the antibiotics could be achieved by the use of low-cost fermentation substrates. Two hyper penicillin producing mutant strains of $P$. chrysogenum, UVP1 and UVP2, with $70 \%$ increase in penicillin production over the parent strain were obtained by mutating a wild strain of $P$. chrysogenum (PCL 501) with UV irradiation. Cheaper and more effective penicillin antibiotics could be obtained by fermenting the UVinduced mutant strains of $P$. chrysogenum on the agro-wastes ${ }^{[6]}$. Residual plant materials in the urban refuse can also serve as cheap carbon and energy sources for fermentation instead of refined sugars such as glucose and lactose ${ }^{[7,8]}$. This could turn the recalcitrant waste plant biomass into a valuable resource and reduce the pollution problem caused by its accumulation in the environment ${ }^{[9,10]}$. In Nigeria, agro-industrial wastes abound in the form of wood-wastes and crop residues such as cassava peels, corncobs, sawdust and sugarcane pulp ${ }^{[11]}$. In this study, a strain of P. chrysogenum (PCL501) was fermented on cassava peels - a waste cellulosic materials produced in Lagos, Nigeria and the culture extract was tested for antibiotic activity against two clinical bacterial isolates (Bacillus subtilis and Escherichia coli). The fungus thrives on sawdust and sugar cane pulp ${ }^{[12]}$ and produces hydrolytic enzymes such as cellulases ${ }^{[13]}$ pectinases ${ }^{[14]}$ and xylanases ${ }^{[15]}$ in media containing agro-wastes. The present results show that $P$. chrysogenum (PCL501) fermented with cassava peels produces effective antibiotics with antibiotic activity comparable to commercial benzyl penicillin (Retarpen, Sandox, Austria). Cassava peels were indicated as suitable low-cost substrates for the production of antibiotics by the strain of $P$. chrysogenum. 


\section{Preparations of Agro-waste materials}

\section{METHODS}

Cassava peels (Manihot esculenta) was purchased from a local market in Mushin, Lagos, Nigeria. The material was dried at $80^{\circ} \mathrm{C}$ to constant weight in the oven, and milled using Marlex Exceller grinder (Mumbai, India). Fine powder obtained after passing each through a sieve of $0.5 \mathrm{~mm}$ pore size was used as a substrate in the fermentation media.

\section{Penicillium chrysogenum PCL501}

The strain of P. chrysogenum (PCL501) used for this study was isolated from a wood-waste dump in Lagos, Nigeria and characterized as described previously ${ }^{[16]}$. The organism was maintained on PDA slant at $4^{\circ} \mathrm{C}$.

\section{Growth culture and penicillin production}

The fungus was sub-cultured on PDA plates and incubated at $30^{\circ} \mathrm{C}$ for $3-5$ days to obtain the spores used for antibiotics production. Spores were washed into a sterile beaker using $0.1 \%$ Tween 80 in $0.1 \mathrm{M}$ potassium phosphate buffer at $\mathrm{pH}$ 7.0. The spore suspension was standardized such that 1 in 10 dilutions has an Absorbance of 0.48 at $530 \mathrm{~nm}$. Fifty milliliters $(50 \mathrm{ml})$ of the spore suspension was aseptically introduced into a litre of sterile fermentation media containing per litre of distilled water: $6.0 \mathrm{~g}$ Ammonium acetate, $0.5 \mathrm{~g} \mathrm{NaSO}$, $0.02 \mathrm{~g} \mathrm{ZnSO}_{4} .7 \mathrm{H}_{2} \mathrm{O}, 0.25 \mathrm{~g} \mathrm{MgSO}_{4} .7 \mathrm{H}_{2} \mathrm{O}, 6.0 \mathrm{~g} \mathrm{KH}_{2} \mathrm{PO}_{4}, 0.02 \mathrm{~g} \mathrm{FeSO} .7 \mathrm{H}_{2} \mathrm{O}, 0.5 \mathrm{~g}$ Phenylalanine, and $10.0 \mathrm{~g}$ cassava peels as a carbon source. The $\mathrm{pH}$ was adjusted to 6.0. The flasks were incubated with intermittent shaking for 7 days.

\section{Standard Reference Drug}

Benzyl penicillin (Retarpen, Sandox, Austria) was purchased from the Community Pharmacy at the College of Medicine, University of Lagos. Sixteen (16) $\mathrm{mg} / \mathrm{ml}$ of the drug in $0.1 \mathrm{M}$ potassium phosphate buffer $(\mathrm{pH} 7)$ was used as reference drug for the in vitro and in vivo tests.

\section{Clinical Bacterial Isolates}

Clinical isolates of Bacillus subtilis and Escherichia coli used for the study were provided by the Department of Medical Microbiology and Parasitology, College of Medicine, University of Lagos, Nigeria.

\section{Antibiotic Sensitivity Testing}

Antibacterial activity of the culture extracts was assayed. Nutrient agar plates were seeded with $0.1 \mathrm{ml}$ of an overnight culture of each clinical isolate (equivalent to $10^{7}-10^{8} \mathrm{CFU} \mathrm{ml}{ }^{-1}$ ). A sterile cork borer of $8 \mathrm{~mm}$ diameter was used to cut three uniform wells on the surface of the agar after 24 hours of incubation. The wells on each plate were then filled with $0.3 \mathrm{ml}$ of THE culture extract and the effect on the growing "lawns" of each clinical isolate was monitored at intervals of 24 hours. This was repeated using the standard drug. Zones of clearance around each well mean inhibition and the diameter of such zones were measured after a marked decline in the potency of the antibiotics to inhibit the growth of the test organisms was noticed ${ }^{[17]}$.

\section{Extraction of penicillin}

After 7 days of fermentation, culture filtrates were centrifuged at X4000g for 5 minutes to remove cells, $\mathrm{pH}$ of cell-free supernatant adjusted to 2.5, chloroform and 10\% phosphate buffer $\mathrm{pH} 2.5$ (20:1) was added to $9 \mathrm{ml}$ of the culture filtrate, this was mixed and the layers allowed separating. The chloroform layer was drawn into a second separating funnel. A second $20 \mathrm{ml}$ portion of chloroform was added to re-extract, the extracts were combined and washed with one or more $10 \mathrm{ml}$ portions of $1 \%$ phosphate buffer, $\mathrm{pH} 2.5$, the buffer washes were discarded. The penicillin was extracted from the chloroform with $10 \mathrm{ml}$ of $1 \%$ phosphate buffer, $\mathrm{pH}$ 6.0. Each batch of extract was freeze dried to a constant weight at $4^{\mathrm{O}} \mathrm{C}^{[18]}$.

\section{In vivo study to determine the effect of Natural Penicillin following $E$. coli infection}

Twenty Wistar rats weighing approximately 200 grams were used for this study. The rats were separated into 4 groups (of five rats each). E. coli infection was done by injecting $0.5 \mathrm{ml}$ cell suspension of overnight broth culture into the subcutaneous layer of the right thigh of the rats ${ }^{[19]}$. These animals were observed after $6-12 \mathrm{hrs}$. Group A: Infected with E. coli.

B: Infected with E. coli

C: Negative control (E. coli infected, no treatment was given).

D: Positive control (Normal rats)

Group A: was administered with extracts of $P$. chrysogenum from cassava peels $(1500 \mathrm{mg} / \mathrm{kg}$ body weight in divided doses of $750 \mathrm{mg} / \mathrm{kg}$ body weight twice daily) for 7 days.

B: was administered with commercial Benzyl penicillin $(1500 \mathrm{mg} / \mathrm{kg}$ body weight in divided doses of $750 \mathrm{mg} / \mathrm{kg}$ body weight twice daily) for 7 days. 
Groups C and D were fed normally and no treatment was given

Blood samples were taken $24 \mathrm{hrs}$ before infecting the rats, this served as the control. For in vivo biochemical analysis of infected Wistar rats, blood was collected $24 \mathrm{hrs}$ after bacterial infection with E. coli. Extract and reference drug were administered for 7 days. Blood was subsequently collected 4 days, 8 days and 14 days after commencement of administration of extract and reference drug to respective groups.

Liver function tests (AST, ALT, Alkaline phosphatase and bilirubin), kidney function tests, were assessed to evaluate the therapeutic effect of the culture extracts.

\section{Determination of haematological parameters}

The determination of haematological parameters (haemoglobin concentration, packed cell volume, total white blood cell count, platelet count, neutrophils and lymphocytes) was carried out according to the method of Dacie and Lewis ${ }^{[20]}$.

\section{Determination of Biochemical indices}

Total bilirubin concentration was determined using the methods of Balistreri and Shaw ${ }^{[21]}$, urea and creatinine by the method of Tietz ${ }^{[2]}$, activity of AST and ALT was assayed by the methods of Reitman and Frankel ${ }^{[23]}$, while activity of alkaline phosphatase (ALP) was assayed by the method of Klein et al., ${ }^{[24]}$ as outlined in Randox kits, UK. The determination of $\mathrm{Na}^{+}$and $\mathrm{K}^{+}$using flame photometer as described by Chuang et al., [ ${ }^{25]}$; Chloride was assayed as described by Cheessbrough ${ }^{[26]}$. The determination of activities of SOD, Catalase, and levels of Glutathione and MDA were carried out as described by Usoh et al., ${ }^{[27]}$.

Statistical Analysis

Data were presented as mean \pm SEM. Statistical analysis was performed using ANOVA Statistical Package for the Social Sciences (SPSS) version 22.0, p-value less than 0.05 ( $p<0.05$ ) was considered to be significant.

Table 1: Zone of inhibition and potency of culture extracts of Penicillium chrysogenum PCL501 and Reference drug against clinical isolates of $E$. coli and $B$. subtilis

\begin{tabular}{|c|c|c|c|c|c|}
\hline \multirow{2}{*}{$\begin{array}{l}\text { Source of } \\
\text { Antibiotics }\end{array}$} & \multirow{2}{*}{$\begin{array}{l}\text { Carbon Source } \\
\text { of culture } \\
\text { media }\end{array}$} & \multicolumn{2}{|c|}{ Escherichia coli } & \multicolumn{2}{|c|}{ Bacillus subtilis } \\
\hline & & $\begin{array}{l}\text { Diameter of } \\
\text { inhibition zone } \\
(\mathrm{mm})\end{array}$ & $\begin{array}{l}\text { Potency of } \\
\text { antibiotic } \\
(\mathrm{mg} / \mathrm{ml})\end{array}$ & $\begin{array}{l}\text { Diameter of } \\
\text { inhibition } \\
\text { zone }(\mathrm{mm})\end{array}$ & $\begin{array}{l}\text { Potency of } \\
\text { antibiotic } \\
(\mathrm{mg} / \mathrm{ml})\end{array}$ \\
\hline $\begin{array}{l}\text { culture extract of } \\
\text { P. chrysogenum } \\
\text { PCL501 }\end{array}$ & Cassava peels & $15.12 \pm 0.03$ & 11.76 & $26.6 \pm 0.14$ & 10.43 \\
\hline $\begin{array}{l}\text { Reference } \\
\text { antibiotic } \\
\text { (Penicillin G) }\end{array}$ & Not applicable & $16.93 \pm 0.50$ & 16.00 & $34.46 \pm 0.50$ & 16.00 \\
\hline
\end{tabular}

In vivo biochemical effects of Natural Penicillin on chemical analytes involved in liver function

Biochemical test of serum enzymes used as indicators of liver function - Aspartate Transaminase (AST), Alanine Transaminase (ALT), Bilirubin (Total and Direct), Alkaline Phosphatase (ALP), were assayed. Results obtained after 24 hours post infection with E.coli (Table 3) shows an increase $(\mathrm{p}<0.05)$ in the liver enzymes AST, ALT, ALP, as well as Bilirubin (Total and Direct). These parameters gradually decreased in the course of treatment and returned to normal range by the eight-day post treatment. There was no significant $(p>0.05)$ difference in all the liver function markers when the tests were repeated 14 days post treatment.

Table 2 Biochemical changes in liver function indices following E.coli infection and treatment with Natural Penicillin and reference drug.

\begin{tabular}{|c|c|c|c|c|c|}
\hline \multirow{3}{*}{ Control } & \multirow[t]{2}{*}{ AST (IU/L) } & \multirow[t]{2}{*}{ ALT (IU/L) } & \multicolumn{2}{|c|}{ BILIRUBIN $\mu \mathrm{mol} / \mathrm{L}$} & \multirow[t]{2}{*}{ ALP (IU/L) } \\
\hline & & & Total & Direct & \\
\hline & $3.86 \pm 1.02$ & $3.86 \pm 0.16$ & $54.89 \pm 0.06$ & $41.38 \pm 0.05$ & $11.58 \pm 0.34$ \\
\hline \multicolumn{6}{|c|}{ DAY 1} \\
\hline E.coli & $51.16 \pm 0.84^{*}$ & $19.33 \pm 0.50 *$ & $93.02 \pm 0.13^{*}$ & $61.22 \pm 0.06^{*}$ & $39.41 \pm 0.96^{*}$ \\
\hline \multicolumn{6}{|c|}{ DAY 4} \\
\hline EcRd & $36.24 \pm 0.18^{*}$ & $10.62 \pm 0.08 *$ & $57.97 \pm 0.08^{*}$ & $53.35 \pm 0.15^{*}$ & $26.42 \pm 0.34 *$ \\
\hline EcEx & $38.64 \pm 0.91 *$ & $12.12 \pm 0.37 *$ & $60.53 \pm 0.10^{*}$ & $48.05 \pm 0.04 *$ & $29.62 \pm 0.96 *$ \\
\hline \multicolumn{6}{|c|}{ DAY 8} \\
\hline EcRd & $12.08 \pm 0.27^{*}$ & $4.13 \pm 0.22 *$ & $53.35 \pm 0.05$ & $24.28 \pm 0.04$ & $12.39 \pm 0.17$ \\
\hline
\end{tabular}


Physiological effect of Natural Penicillin Extract on Cassava Peel Media by Penicillium chrysogenum

\begin{tabular}{|l|c|c|c|c|c|}
\hline EcEx & $14.49 \pm 0.87 *$ & $7.72 \pm 0.32 *$ & $48.91 \pm 0.10$ & $22.74 \pm 0.02$ & $13.16 \pm 0.26$ \\
\hline \multicolumn{5}{|c|}{ DAY 14 } \\
\hline EcRd & $4.08 \pm 0.79$ & $4.01 \pm 0.10$ & $54.55 \pm 0.13$ & $34.78 \pm 0.06$ & $11.89 \pm 0.31$ \\
\hline EcEx & $3.99 \pm 0.37$ & $5.12 \pm 0.37$ & $53.77 \pm 0.18$ & $40.702 \pm 0.10$ & $11.33 \pm 0.33$ \\
\hline
\end{tabular}

Legend

$*=$ Significant values $(\mathrm{p}<0.05) \quad$ Values are expressed as mean \pm SEM

E.coli - group infected with E.coli

EcRd - group treated with Reference drug after infection with E. coli

EcEx - group treated with extract after infection with $E$. coli

In vivo biochemical effects of Natural Penicillin on chemical analytes involved kidney function

In vivo biochemical changes in renal function markers - urea, creatinine and the electrolytes $\left(\mathrm{Na}^{+}, \mathrm{K}^{+}\right.$, and $\mathrm{Cl}^{-}$) after infection of experimental animals with E.coli were monitored for 14 days (Table 3). Results obtained 24 hours post-infection showed a significant increase $(p<0.05)$ in all the parameters assayed. These parameters gradually decreased in the course of treatment and returned to normal when compared with the control groups by the end of the eight-day post treatment. Tests results repeated 14 days post treatment showed no significant difference ( $p>0.05$ ) between the control and the experimental groups.

Table 3: Biochemical changes in renal function indices following E.coli infection and treatment with Natural Penicillin of P.chrysogenum and reference drug

\begin{tabular}{|c|c|c|c|c|c|}
\hline & $\mathrm{Na}^{+}$ & $\mathbf{K}^{+}$ & $\mathrm{Cl}^{-}$ & $\mathbf{U r}$ & $\mathrm{Cr}$ \\
\hline & $\mathrm{mMol} / \mathrm{L}$ & $\mathrm{mMol} / \mathrm{L}$ & MEq/L & $\mathrm{mMol} / \mathrm{L}$ & $\mu \mathrm{Mol} / \mathrm{L}$ \\
\hline Control & $109.2 \pm 1.30$ & $4.2 \pm 0.08$ & $98 \pm 0.84$ & $9.72 \pm 0.09$ & $75.46 \pm 0.65$ \\
\hline \multicolumn{6}{|c|}{ DAY 1} \\
\hline E.coli & $120.2 \pm 1.48 *$ & $4.2 \pm 0.07$ & $107 \pm 0.55$ & $12.77 \pm 0.08 *$ & $120.74 \pm 0.53 *$ \\
\hline \multicolumn{6}{|c|}{ DAY 4} \\
\hline EcRd & $140.2 \pm 1.31 *$ & $4.6 \pm 0.11$ & $96 \pm 1.14$ & $12.52 \pm 0.08 *$ & $112.12 \pm 0.44 *$ \\
\hline EcEx & $123.2 \pm 0.84 *$ & $5.1 \pm 0.08$ & $112 \pm 1.14$ & $11.61 \pm 0.10^{*}$ & $103.49 \pm 0.84 *$ \\
\hline \multicolumn{6}{|c|}{ DAY 8} \\
\hline EcRd & $128.4 \pm 1.14 *$ & $4.3 \pm 0.22$ & $95 \pm 0.84$ & $10.05 \pm 0.27 *$ & $94.87 \pm 0.29 *$ \\
\hline EcEx & $115.2 \pm 1.30 *$ & $4.3 \pm 0.07$ & $92 \pm 0.70$ & $9.98 \pm 0.26$ & $81.93 \pm 0.66^{*}$ \\
\hline \multicolumn{6}{|c|}{ DAY 14} \\
\hline EcRd & $118.4 \pm 1.10$ & $4.2 \pm 0.22$ & $95 \pm 1.14$ & $9.05 \pm 0.07$ & $78.87 \pm 0.10$ \\
\hline EcEx & $110.1 \pm 1.30$ & $4.1 \pm 0.07$ & $92 \pm 0.70$ & $9.18 \pm 0.10$ & $74.93 \pm 0.09$ \\
\hline
\end{tabular}

$*=$ Significant values $(\mathrm{p}<0.05)$

Legend

E.coli - group infected with E.coli

EcRd - group treated with Reference drug after infection with E. coli

EcEx - group treated with extract after infection with E. coli

In vivo biochemical effects of Natural Penicillin on antioxidant enzymes and oxidation product

Test results after 24 hours post-infection with E.coli (Table 4) showed a significant increase $(\mathrm{p}<0.05)$ in the activities of enzymes involved in oxidative stress following infection when compared to the control. There was also an increase in MDA- a product of lipid peroxidation and is indicative of oxidative stress. These enzymes and MDA gradually decreased in the course of treatment and returned to normal when compared with the control group by the end of the eight day post treatment. However tests repeated 14 days after shows no significant $(\mathrm{p}>0.05)$ difference in all the enzymes and MDA monitored.

Table 4: Biochemical changes in antioxidant enzymes and oxidation product following E.coli infection and treatment with Natural Penicillin and reference drug

\begin{tabular}{|l|c|c|c|c|}
\hline & CAT & SOD & GSH & MDA \\
\hline & $\boldsymbol{\mu M o l} / \mathbf{m l}$ & $\begin{array}{c}\boldsymbol{\mu M o l} / \mathbf{m l} \\
\mathbf{m g} / \mathbf{m l}\end{array}$ & $\boldsymbol{\mu M o l} / \mathbf{m L}$ & $\mathbf{n M o l} / \mathbf{m l}$ \\
\hline Control & $2.75 \pm 0.36$ & $117.63 \pm 0.99$ & $1.54 \pm 0.03$ & $5.29 \pm 0.14$ \\
\hline \multicolumn{5}{|c|}{ DAY 1} \\
\hline
\end{tabular}


Physiological effect of Natural Penicillin Extract on Cassava Peel Media by Penicillium chrysogenum `

\begin{tabular}{|l|c|c|c|c|}
\hline E.coli & $7.45 \pm 0.22^{*}$ & $311.08 \pm 0.64^{*}$ & $2.32 \pm 0.11^{*}$ & $10.64 \pm 0.16^{*}$ \\
\hline \multicolumn{5}{|c|}{ DAY 4} \\
\hline EcRd & $3.93 \pm 0.21^{*}$ & $193.47 \pm 0.58^{*}$ & $1.05 \pm 0.06^{*}$ & $10.56 \pm 0.06^{*}$ \\
\hline EcEx & $5.55 \pm 0.09^{*}$ & $208.64 \pm 0.77^{*}$ & $1.31 \pm 0.13^{*}$ & $14.15 \pm 0.46^{*}$ \\
\hline \multicolumn{5}{|c|}{ DAY 8} \\
\hline EcRd & $2.85 \pm 0.14$ & $128.98 \pm 0.39^{*}$ & $0.68 \pm 0.02$ & $3.33 \pm 0.07$ \\
\hline EcEx & $3.14 \pm 0.21$ & $144.15 \pm 0.57^{*}$ & $0.94 \pm 0.01$ & $4.46 \pm 0.08$ \\
\hline \multicolumn{5}{|c|}{} \\
\hline EcRd & $2.65 \pm 0.11$ & $118.98 \pm 0.17$ & $1.38 \pm 0.02$ & $4.23 \pm 0.25$ \\
\hline EcEx & $3.01 \pm 0.09$ & $114.15 \pm 0.27$ & $1.64 \pm 0.03$ & $5.46 \pm 0.22$ \\
\hline
\end{tabular}

$*=$ Significant values $(\mathrm{p}<0.05) \quad$ Values are expressed as mean \pm SEM

Legend

E.coli - group infected with E.coli

EcRd - group treated with Reference drug after infection with E. coli

EcEx - group treated with extract after infection with $E$. coli

\section{In vivo biochemical effect of Natural Penicillin and reference drug on haematology indices}

Twenty-four-hour post-infection analysis of haematology indices showed a significant decrease $(\mathrm{p}<0.05)$ in PCV, Hb and platelet values and a significant increase $(\mathrm{p}<0.05)$ in $\mathrm{WBC}$ and WBC differentials count in group infected with E.coli (Table 5). Results obtained four days after the commencement of treatment in the group when compared to the 24hour results showed a significant decrease $(\mathrm{p}<0.05)$ in $\mathrm{PCV}$ and $\mathrm{Hb}$ concentration indicating anaemia, also a significant decrease in platelets count was observed indicating thrombocytopenia. A significant increase $(\mathrm{p}<0.05)$ in $\mathrm{PCV}, \mathrm{Hb}$ and platelets count was observed eight days from the administration of the extract. Results obtained 14 days after show normal haematology indices.

Table 5: Changes in haematology indices following $E$. coli infection and treatment with Natural Penicillin and reference drug.

\begin{tabular}{|c|c|c|c|c|c|c|c|}
\hline & $\mathbf{P C V}$ & HB & Platelets & WBC & $\mathbf{N}$ & & M \\
\hline & $\%$ & $\mathrm{~g} / \mathrm{L}$ & $10^{3} / \mathrm{L}$ & $\begin{array}{l}/ \mathrm{mm2} 2 \\
\left(\mathbf{x 1 0 ^ { 3 }}\right)\end{array}$ & $\%$ & $\%$ & $\%$ \\
\hline Control & $40.2 \pm 1.30$ & $13.4 \pm 0.43$ & $196 \pm 1.92$ & $4.1 \pm 70.71$ & $52 \pm 1.41$ & $48 \pm 1.41$ & $0 \pm 0.00$ \\
\hline \multicolumn{8}{|c|}{ DAY 1} \\
\hline E.coli & $22.4 \pm 0.55^{*}$ & $7.5 \pm 0.18 *$ & $173 \pm 2.88^{*}$ & $6.4 \pm 70.71 *$ & $33 \pm 1.22 *$ & $\begin{array}{c}65 \\
\pm 1.22 *\end{array}$ & $2 \pm 0.0$ \\
\hline \multicolumn{8}{|c|}{ DAY 4} \\
\hline EcRd & $26.4 \pm 2.07 *$ & $8.8 \pm 0.69 *$ & $159 \pm 2.12 *$ & $6.8 \pm 70.71 *$ & $48 \pm 1.00 *$ & $\begin{array}{c}52 \\
\pm 1.00 *\end{array}$ & $0 \pm 0.0$ \\
\hline EcEx & $25.4 \pm 1.14 *$ & $8.5 \pm 0.38 *$ & $161 \pm 1.30^{*}$ & $8.5 \pm 70.71 *$ & $40 \pm 1.41^{*}$ & $\begin{array}{c}59 \\
\pm 0.71 *\end{array}$ & $1 \pm 0.0$ \\
\hline \multicolumn{8}{|c|}{ DAY 8} \\
\hline EcRd & $27.2 \pm 0.84 *$ & $9.1 \pm 0.28 *$ & $150 \pm 2.13^{*}$ & $4.4 \pm 70.71$ & $50 \pm 1.58$ & $49 \pm 1.22$ & $1 \pm 0.0$ \\
\hline EcEx & $29.4 \pm 1.52 *$ & $9.8 \pm 0.51 *$ & $158 \pm 1.14 *$ & $5.3 \pm 70.71$ & $39 \pm 0.71$ & $61 \pm 1.22$ & $0 \pm 0.0$ \\
\hline \multicolumn{8}{|c|}{ DAY 14} \\
\hline EcRd & $36.6 \pm 1.30$ & $12.1 \pm 0.43$ & $161 \pm 1.92$ & $4.5 \pm 70.71$ & $48 \pm 1.41$ & $51 \pm 1.41$ & $1 \pm 0.0$ \\
\hline EcEx & $38.3 \pm 1.31$ & $12.8 \pm 0.44$ & $167 \pm 1.93$ & $4.6 \pm 70.72$ & $51 \pm 1.42$ & $49 \pm 1.42$ & $0 \pm 0.0$ \\
\hline
\end{tabular}

$*=$ Significant values $(\mathrm{p}<0.05)$

Legend

E.coli - group infected with E.coli

EcRd - group treated with Reference drug after infection with E. coli

EcEx - group treated with extract after infection with $E$. coli 


\section{DISCUSSION}

The natural penicillin extracts of $P$. chrysogenum PCL501 exhibited significant antibacterial effects against clinical isolates of $E$. coli and B. subtilis. The results show that the organism produces natural penicillin that is effective against the two bacterial isolates. This is consistent with the fact that most strains of $P$. chrysogenum produce $\beta$-lactam antibiotics, mainly penicillins ${ }^{[1]}$. The fact that the antibacterial effect of this extract is comparable with that obtained with commercial benzyl penicillin (Retarpen, Sandox, Austria) indicate the prospect of $P$. chrysogenum (PCL501) as a potential source of commercial antibiotics. This is evident in the diameter of clearance zone, and potency of the culture extract.

It is interesting to note that the organism produced natural penicillin in media containing refined sugars (glucose) as well as cassava peels as sole carbon source. Most studies on suitable substrates for penicillium fermentation had centred on the use of refined substrates such as glucose, sucrose, glycerol, galactose and lactose ${ }^{[28]}$. The present result indicates that cassava peels are a good substrate for natural penicillin production by $P$. chrysogenum PCL501. Several studies have shown that the organism thrives on waste plant materials and utilizes the structural carbohydrates for its growth ${ }^{[12,13,29]}$. The organism is known to produce a variety of hydrolytic enzymes, particularly cellulases ${ }^{[13]}$ and xylanases $[30,31]$ which hydrolyse plant cell wall polysaccharides thereby enabling it to utilize the polymers for its carbon and energy needs.

Culture extracts from cassava peels media, yielded antibacterial effects that are comparable to culture extracts from media containing equivalent amount of glucose. This indicates that the agro-waste can effectively serve as cheap fermentation substrate for the production of antibiotics by the strain of $P$. chrysogenum. Nigeria ranks among the highest producer of cassava tubers in the world and cassava peels is a common domestic and agro-industrial waste in the country ${ }^{[32]}$. The use of this material, which is abundant in rural and urban refuse, in antibiotic production will not only lead to a reduction in the production cost of penicillin but also a reduction in pollution-load.Because the liver is the seat of protein synthesis and drug metabolism, the measurement of the activities of marker and diagnostic enzymes (aspartate transaminase (AST), alanine transaminase (ALT) and alkaline phosphatase (ALK), ) in liver tissues plays a significant role in diagnosis and disease investigation and in the assessment of drug or plant extract safety or toxicity. It is well known that an increase in the activity of liver enzymes in the serum is indicative of cellular leakage and loss of functional integrity of cellular membrane of the liver ${ }^{[19]}$. Among the different isoenzymes of ALK, the one originating from the liver has been shown to be the main component of the serum ${ }^{[33]}$. ALT and AST, on the other hand, are localized within the cells of the liver and other organs and are of major importance in monitoring and assessing liver cytolysis ${ }^{\text {[34] }}$.

In this research, it was observed that these enzymes were raised in animals infected with E.coli and that these parameters gradually decreased in the course of treatment with the natural penicillin and reference drug groups and returned to normal by the $8^{\text {th }}$ to $14^{\text {th }}$-day post treatment. The natural penicillin produced significantly lowered the level of the serum enzymes in the animals infected with E. coli. This reaffirms the earlier conclusion that the extract is an antibiotic. These findings agree with an earlier report by Yakubu et al., ${ }^{[34]}$ that serum activities s of transaminases returned to normal with the healing of hepatic parenchyma and regeneration of hepatocytes. Changes in bilirubin values were also examined under these conditions because the liver is the seat of conjugation of bilirubin; therefore, increase the amount of circulating unconjugated bilirubin is suggestive of hepatobiliary dysfunction. The normal range for unconjugated bilirubin is $3.42-17.1 \mu \mathrm{mol} / \mathrm{l}$, while the normal range for conjugated bilirubin is $1.7-3.42 \mu \mathrm{mol} / \mathrm{l}^{[33]}$. The results obtained from the assay of bilirubin shows that the bilirubin values obtained from the animals infected with E.coli were higher than that of the control. This could be due to red cell destruction caused by the infecting organism. These are stress conditions that may manifest as jaundice. There is a growing body of evidence that prolonged use of some $\beta$ lactam antibiotics (amoxicillin-clavulanic acid), which is a widely used antibiotic, has been associated with an increased incidence of cholestatic jaundice and acute hepatitis during therapy or shortly after, particularly in men and those aged over 65 years. The associated jaundice is usually self-limiting and very rarely fatal. Until 1993 the UK Committee on Safety of Medicines (CSM) has received 138 reports of hepatobiliary disorders (three fatal) with amoxicillin-clavulanic acid. $12 \%$ of all suspected adverse reactions reported with amoxicillinclavulanic acid were in the hepatobiliary system. They, therefore, recommended that treatments such as amoxicillin/clavulanic acid preparations should be reserved for bacterial infections likely to be caused by amoxicillin-resistant $\beta$-lactamase-producing strains, and that treatment should not normally exceed 14 days ${ }^{[35]}$. Bilirubin result in this study does not suggest the natural penicillin cause any biochemical abnormality or liver insufficiency.

When the level of electrolytes in the body changed, the water content in the cells also changes. These changes can be associated with dehydration (shrinking) or excess fluid (oedema), due to inflammation of the tissues. Similarly, in the presence of normal renal blood flow, any increases in urea $(17.8$ to $35.0 \mathrm{mmol} / \mathrm{L})$ and creatinine values (110 to $150 \mu \mathrm{mol} / \mathrm{L})$ are suggestive of moderate to severe kidney damage ${ }^{[36]}$. Therefore this study, has taken steps to examine the effect of the extract on kidney functions.Results obtained 24 hours postinfection with $E$. coli showed increase in $\mathrm{Na}^{+}$, urea and creatinine levels and no observed elevation in $\mathrm{K}^{+}$and $\mathrm{Cl}^{-}$ 
values. These elevated parameters gradually decreased in the course of treatment with the natural penicillin and returned to normal range when compared to the control groups by the end of the 14th-day post treatment. This result suggest that the increases in the levels of renal function parameters observed was due to the presence of infection, this is a transient event which did not cause any renal insufficiency. It also indicates that the natural penicillin had influence on the kidney in regulating and maintaining electrolyte, urea and creatinine balance in the body. Cells have a comprehensive array of antioxidant defence mechanisms to reduce free radical formation or limit their damaging effects. Antioxidant enzyme-dependent defences play an important role in scavenging free radicals produced under oxidative stress. These include enzymes such as superoxide dismutase (SOD) and catalase CAT) to degrade superoxide and peroxides respectively, and essential radical scavengers, such as glutathione reductase $(\mathrm{GSH}){ }^{[37]}$. In the presence of infection with E.coli, activities of these enzymes and oxidation product were increased. These parameters gradually decreased in the course of treatment with the extract and reference drug and returned to normal by the end of the $8^{\text {th }}$ to $14^{\text {th }}$-day post treatment. The observed elevation indicates an increase in generation of free radicals in the system of the infected rats beyond the capacity of the body system to handle as it does in normal cell metabolism hence the manifestation of inflammation. The significantly elevated activities of SOD, CAT and levels of GSH and MDA in all the rats infected with E.coli agree with previous studies that these enzymes (SOD and CAT) are inducible in mammals and microorganism ${ }^{[38]}$, and their levels will increase with increasing need to protect against toxic oxidation ${ }^{[39}$, ${ }^{40]}$. Similarly, it has been observed that antioxidant enzyme-dependent defences play an important role in scavenging free radicals produced under oxidative stress ${ }^{[41]}$. Approximately $99 \%$ of Glutathione in brain cells exist in the reduced form (GSH). By serving as an electron donor, GSH plays an important role by removing hydrogen peroxides, thus protecting cells from oxidative stress. A decreased level of glutathione indicates decreased scavenging capacity of the glutathione-dependent anti-oxidant defensive system against elevated lipid peroxidation processes. Haematological indices, except for WBC, were decreased in the presence of infection with $E$. coli. These values gradually returned to normal after treatment with the natural penicillin and reference drug, but low platelet values were observed even after the treatment was stopped. Low platelet values depict thrombocytopenia caused by the extract and reference drug in the host cells. Blood normally contains 150,000 to $350,000 / \mu 1$. If this value should drop much below $50,000 / \mu 1$, there is a danger of uncontrolled bleeding. This is because platelets aggregation is an important step during blood clotting and it has been observed that penicillin $\mathrm{G}$ and related antibiotics may be inhibitory to platelets function because they coat the platelet surface ${ }^{[42]}$. Their effects on platelet functions are probably responsible for excessive bleeding and increased bleeding times observed in patients and volunteers receiving high doses of these antibiotics ${ }^{[43]}$.

\section{CONCLUSION}

This study has demonstrated that cassava peels are a viable substrate for the fermentation media used in cultivating the fungus for the production of natural penicillin antibiotics. This is very significant considering the fact that this substrate is produced in very large quantities during processing. Therefore, rather than using synthetic media containing glucose, low-cost microbial media can be formulated with cassava peels as the sole carbon and energy source. The advantage over the industrial synthetic substrates is that it is natural, readily available, sustainable, cost-effective and environmentally friendly.

\section{REFERENCES}

[1] De Hoog, G.S., Guarro, J., Figueras, M.J. and Gene, J. Atlas of Clinical Fungi. 2nd ed. Centraalbureau voor Schimmelcultures, Utrecht, The Netherlands and Universitat Rovirai Virgili, Reus, Spain, 2000;1124.

[2] Backus, M.P. and Stauffer, J.F. The production and selection of a family of strains in Penicillium chrysogenum. Mycologia, 1955; 47:429-463.

[3] Veerapagu M, Jeya, K. R., Ponmurugan K. Mutational effect of Penicillium chrysogenum on Antibiotic Production. Advanced Biotechnology, 2008; 16-19.

[4] Chuan-Bao., Sun Qiu-Lian and Kong Wen-Si Xu. Efficient transformation of Penicillium chrysogenum mediated by Agrobacterium tumefaciens LBA4404 for cloning of Vitreoscilla hemoglobin gene. Electronic Journal of Biotechnology, 2002; 5 (1):1- 8.

[5] Veenhuis M. Penicillin production by Penicillium chrysogenum: role of the microbody membrane in the penicillin biosynthetic pathway. Electronic Molecular Biology and Genetics, Journal of Biotechnology, 2002; 5: 717-3458.

[6] Onyegeme-Okerenta, B. M., Okochi, V. I. and Chinedu, S.N. Penicillin Production by Penicillium chrysogenum PCL 501: Effect of UV Induced Mutation. International Journal of Microbiology, 2013; 12(1): $1-7$. 
[7] Howard, R.L.I., Abotsi, E., Jansen Van Rensburg, E.L.I. and Howard, S. Lignocellulose biotechnology: issues of bioconversion and enzyme production. Review. African Journal of Biotechnology, 2003; 2(12): 602-619.

[8] Onyegeme-Okerenta, B. M., Chinedu, S. N., Okochi, V. I. and Okafor, U. A. Agro-waste: A potential fermentation substrate for Penicillium chrysogenum. International Journal of Biological and Chemical Sciences, 2009; 3 (2): 203-208.

[9] Adney, W.S., Rivard, C.J., Ming, S.A., and Himmel, M.E. Anaerobic Digestion of Lignocellulosic Biomass and Wastes. Cellulases and Related Enzymes. Applied Biochemistry and Biotechnology, 1999; 30: $165-183$.

[10] Rahman, A.M.T.F., Kyesmu, P.M., Tom, T.U. Biodegradation of wheat and corn offal for poultry feed production. Proceedings of the International Conference on Biotechnology: Commercialization and Food security. Abuja, Nigeria, 2000; 63-71.

[11] Abu, E.A., Onyenekwe, P.C., Ameh, D.A., Agbaji, A.S., and Ado, S.A. Cellulase (EC 3.2.1.3) production from sorghum bran by Aspergillus niger SL1: An assessment of pretreatment methods. Proceedings of the International Conference on Biotechnology: Commercialization and Food security. Abuja, Nigeria, 2000; 153-157.

[12] Nwodo-Chinedu, S., Okochi, V.I., Omidiji, O., Omowaye, O.O., Adeniji, B.R., Olukoju, D. and Chidozie, F. Potentials of cellulosic wastes in media formulation. African Journal of Biotechnology, 2007; 6 (3): 243-246.

[13] Nwodo-Chinedu, S., Okochi, V.I., Smith, H.A., Okafor, U.A., Onyegeme-Okerenta, B.M. and Omidiji, O. Effect of carbon sources on cellulase (EC 3. 2. 1. 4) Production by wild-type Penicillium chrysogenum PCL501. African Journal of Biochemistry Research, 2007; 1 (1): 6-10.

[14] Okafor, U. A., Okochi, V. I., Nwodo Chinedu, S., Ebuehi, O. A. T. and Onygeme-Okerenta, B. M. Pectinolytic activity of wild-type filamentous fungi fermented on agro-wastes. African Journal of Microbiology Research, 2010; 4(24): 2729-2734.

[15] Okafor, U. A., Emezue T. N., Okochi V. I., Onyegeme-Okerenta B. M. and Nwodo-Chinedu, S. Xylanase production by Penicillium chrysogenum PCL501 fermented on cellulosic wastes. African Journal of Biochemistry Research, 2007; 1(4): 048-053.

[16] Nwodo-Chinedu, S, Okochi, V.I. Smith, H.A and Omidiji O. Isolation of cellulolytic microfungi involved in wood-waste decomposition: Prospect for enzymatic hydrolysis of cellulosic wastes. International Journal of Biomedical and Health Sciences, 2005; 1(2): 41-51.

[17] Laich, F., Fierro, F. and Martın, J. F. Production of Penicillin by Fungi Growing on Food Products: Identification of a Complete Penicillin Gene Cluster in Penicillium griseofulvum and a Truncated Cluster in Penicillium verrucosum. Applied and environmental microbiology, 2002; 68(3): 1211-1219.

[18] Grau, F. H. and. Halliday, W. J. The Effect of Nutrients on Formation of Penicillin by Washed Mycelium of Penicillium chrysogenum. Department of Bacteriology, University of Queensland, Brisbane, Australia, 1957; 69:207.

[19] Iweala, E. E. J. and Okeke, C. U. Comparative study of the hypoglycaemic and biochemical effects of Catharanthus roseus (Linn) g. Apocynaceae (Madagascar periwinkle) and chlorpropamide (diabenese) on alloxan-induced diabetic rats. Biokemistri, 2005; 17(2): 149-156

[20] Dacie, J.V. and Lewis, S. M. Investigation of haematological disorders. Practical Haematology, Churchill Livingstone Edinburgh, United Kingdom, 2006; 177-180.

[21] Balistreri, W. F. and Shaw, L. M. Liver function. In: Tietz NW, ed. Fundamentals of clinical chemistry, 3rd edition. Philadelphia, W. B. Saunders, 1987: 729-761.

[22] Tietz, N. W. Clinical Guide to Laboratory Tests, 3rd Edition, pp. 7-216, W B. Saunders Co, Philadelphia, 1994.

[23] Reitman, S. and Frankel, S. A colorimetric Method for the Determination of Serum Glutamic Oxalacetic and Glutamic Pyruvic Transaminases. Clinical Chemistry, 1957; 28: 56-63.

[24] Klein, B., Read, P. A. and Babson, L. A. Rapid Method for Quantitative Determination of Serum Alkaline Phosphatase. Clinical Chemistry, 1960; 6: 269-275.

[25] Chuang, F. S, Sarbeck, J. R. and Winefordner, J. D. Flame spectrometric determination of sodium, potassium and calcium in blood serum by measurement of microsamples. Clinical Chemistry, 2005; $21: 16-23$.

[26] Cheesbrough, M. District Laboratory Practice in Tropical Countries, Part 2. Cambridge University Press, 2004. U.K. ISBN 0521665469.

[27] Usoh, I. F., Akpan, E. J., Etim, E. O. and Farombi, E. O. Antioxidant Actions of Dried Flower extract of Hibiscus sabdariffa L. on Sodium arsenite-induced oxidative stress in rats. Pakistan Journal of Nutrition, $2005 ; 4.3: 135-141$. 
[28] Nagy, Z., Keresztessy, Z., Szentirmai, A. and Biro, S. Carbon source regulation of beta-galactosidase biosynthesis in Penicillium chrysogenum. Journal of Basic Microbiology, 2002; 41 (6); 321-362.

[29] Onyegeme-Okerenta, B. M., Nwodo Chinedu, S., Okochi, V. I and Okafor U. A. Agro-waste: potential substrates for Penicillium chrysogenum. International Journal of Biological and Chemical Sciences, 2009; 3 (2): 203-208.

[30] Nwodo Chinedu, S. Okafor, U.A., Emezue, T.N., and Okochi, V.I. Xylanase production of Aspergillus niger and Penicillium chrysogenum from ammonia pretreated cellulosic waste. Research Journal of Microbiology, 2008; 3 (4): 246-253.

[31] Okafor, U. A., Emezue, T. N., Okochi, V. I., Onyegeme-Okerenta, B. M. and Nwodo-Chinedu, S. Xylanase production by Penicillium chrysogenum PCL501 fermented on cellulosic wastes. African Journal of Biochemistry Research, 2007; 1 (4): 048-053.

[32] Jackson, B.A., Oladipo N.O. and Agaja M.O. Cassava: A Potential Crop for Industrial Raw Material in Nigeria. International Journal of Life Sciences, 2014; 3 (3) 105-112.

[33] Vinothkumar, P., Sivaraj, A., Devi, K. and Senthilkumar, B. Hepatoprotective and antioxidant properties of aqueous rhizome extracts of Picrorhiza kurroa on CCl4 induced liver toxicity in Wistar rats. Journal of Pharmacy Research, 2010; 3(6), 1280-1282.

[34] Yakubu, M. T., Oladiji, A. T, and Akanji, M. A. Evaluation of Biochemical indices of male rat reproductive function and testicular histology in Wister rats following chronic administration of aqueous extract of Fadogia agrestis (Schweinf.Extterim) stem. African Journal of Biotechnology, 2007; 1(7) 156168.

[35] Joint Formulary Committee. British National Formulary, 47th edition. British Medical Association and Royal Pharmaceutical Society of Great Britain, London, 2004.

[36] Tietz, N. W. Fundamentals of Clinical Chemistry. $6^{\text {th }}$ Ed. W.B. Saunders co. Philadelphia, 2000: $744-$ 745, 788-789.

[37] Sabari, D., Dinesh, Y., Rajiv, N. and Nibhriti, D. Interrelationship between lipid peroxidation, ascorbic acid and superoxide dismutase in coronary artery disease. Current science, 2002; 83(4): 25.

[38] Elchuri, S., Peskin, C. C. and Campman, F. Cu-ZnSOD Deficiency Leads to Persistent and Widespread Oxidative Damage and Hepatocarcinogenesis Later in Life. Oncogene, 2005; 24: 367-380

[39] Muller, F. L., Li, T. and Groner, Y. Absence of CuZn Superoxide dismutase Leads to Oxidative Stress and Acceleration of Age-Related Muscle Atrophy. Free Radical Biology and Medicine. 2006; 40: 19932004.

[40] Sentman, M. I. and Michels, D. H. Phenotypes of Mice Lacking Extracellular Superoxide dismutase and Copper- and Zinc-containing Superoxide Dismutases. Journal of Biochemistry, 2006; 281:6904-6909.

[41] Soliman, G. Z. A. Blood lipid peroxidation (superoxide dismutase, malondialdehyde, glutathione) levels in Egyptian type 2 diabetic patients. Singapore Medical Journal, 2008; 49(2): 129.

[42] Jean-Pierre, C., Guccione, M. A., Packham, M.A. and Mustard, F. J. Effects of Cephalothin and Penicillin G on Platelet Function in Vitro. British Journal of Haematology, 2008; 35 (1): 135-152.

[43] Onyegeme-Okerenta, B.M., Okochi, V.I. and Chinedu, S.N. Antithrombotic and anticoagulant properties of Penicillium chrysogenum (PCL 501) culture extracts. Journal of Pharmaceutical and Scientific Innovation, 2014; 3 (1):20-24. 